\title{
Effects of Alterations of Plasma Free Fatty Acid Levels on Pancreatic Glucagon Secretion in Man
}

\author{
John E. Gerich, Maurice Langlois, Victor Schneider, John H. Karam, \\ and Claudio Noacco \\ From the Metabolic Research Unit and Department of Medicine, University of \\ California, San Francisco, California 94143
}

A B S T RACT The present investigation was undertaken to ascertain whether alterations in plasma free fatty acids (FFA) affect pancreatic glucagon secretion in man since FFA have been reported to influence pancreatic alpha cell function in other species. Elevation of plasma FFA from a mean ( \pm SE) basal level of $0.478 \pm$ $0.036 \mathrm{mM}$ to $0.712 \pm 0.055 \mathrm{mM}$ after heparin administration caused plasma glucagon levels to fall approximately $50 \%$, from a basal value of $122 \pm 15 \mathrm{pg} / \mathrm{ml}$ to $59 \pm 14$ $\mathrm{pg} / \mathrm{ml}(P<0.001)$. Lowering of plasma FFA from a basal level of $0.520 \pm 0.046 \mathrm{mM}$ to $0.252 \pm 0.041 \mathrm{mM}$ after nicotinic acid administration raised plasma glucagon from a basal level of $113 \pm 18 \mathrm{pg} / \mathrm{ml}$ to $168 \pm 12$ $\mathrm{pg} / \mathrm{ml}(P<0.005)$. Infusion of glucose elevated plasma glucose levels to the same degree that heparin raised plasma FFA levels. This resulted in suppression of plasma glucagon despite the fact that plasma FFA levels also were suppressed. Glucagon responses to arginine were diminished after elevation of plasma FFA $(P<$ $0.01)$ and during infusion of glucose $(P<0.01)$. Diminution of plasma FFA by nicotinic acid did not augment glucagon responses to arginine.

These results thus demonstrate that rather small alterations in plasma FFA within the physiologic range have a significant effect on glucagon secretion in man. Although the effects of glucose appear to predominate over those of FFA, alterations in plasma FFA may nevertheless exert an important physiologic influence over human pancreatic alpha cell function, especially in the postabsorptive state.

\section{INTRODUCTION}

Glucose and amino acids are important factors in the physiologic regulation of human pancreatic glucagon

Received for publication 25 October 1973 and in revised form 7 December 1973. secretion (1). It is currently thought that glucagon plays an important role in human nutrient homeostasis by mobilizing stored substrate when exogenous sources are lacking or when there is an increased demand for metabolic fuel. Data supporting this concept have been derived primarily from studies correlating glucagon secretion with changes in the availability of glucose. However, free fatty acids (FFA) constitute the predominant metabolic fuel on which human tissue subsists. Accordingly if glucagon were to play a role in nutrient homeostasis, one might expect alterations in the availability of FFA to influence pancreatic alpha cell function. Indeed several recent studies (2-9) indicate that FFA may contribute significantly to the control of glucagon secretion. Isolated islets from guinea pigs treated with streptozotocin which contain predominantly alpha cells metabolize octanoic acid preferentially to glucose (2). Diminution of FFA oxidation by means of various metabolic inhibitors augments glucagon release from intact guinea pig islets (3). In contrast the mere addition of FFA to incubation media directly inhibits glucagon secretion $(3,4)$. The results of these in vitro experiments have been supported by several in vivo studies. Elevation of plasma FFA in the dog has been shown to lower plasma glucagon levels (5-7) whereas the depression of plasma FFA in this animal by administration of nicotinic acid causes a rise in plasma glucagon levels (7).

These observations thus suggest that FFA may be important in modulating glucagon secretion in the dog and guinea pig. Since there are no reports to date of comparable studies in man, the present investigation was therefore undertaken to determine the role of FFA in regulating human pancreatic alpha cell function.

\section{METHODS}

Subjects. Research volunteers (three women and five men), 21-26 yr of age, were in apparent good health. None 
had a family history of diabetes mellitus. All had normal glucose tolerance and were nonobese (weight range, 90$105 \%$ ideal body weight according to the Metropolitan Life Insurance Company tables). Possible symptoms and side effects of heparin and nicotinic acid were explained to all subjects before study.

Procedures. All studies were initiated between 7:00 and 8:00 A.M. Subjects arrived at the research unit after a $10-14$-h overnight fast and $0.85 \%$ saline infusion was begun in each arm by means of 19 gauge needles inserted into the antecubital veins. One arm was used for obtaining blood specimens while the other was used for administration of drugs. 30 -min equilibration periods at bed rest were allowed for collection of base-line values before experiments were begun. In one study 5,000 $\mathrm{U}$ heparin (Riker Laboratories, Inc., Northridge, Calif.) was administered by i.v. bolus at 0,15 , and $30 \mathrm{~min}$ in order to elevate plasma FFA levels. In another study $200 \mathrm{mg}$ nicotinic acid (Invenex, San Francisco, Calif.) was administered i.v. over $30 \mathrm{~s}$ at 0 and $15 \mathrm{~min}$ in order to lower plasma FFA levels. In an additional study, glucose was infused at a rate of 350 $\mathrm{mg} / \mathrm{min}$ by a Harvard Pump apparatus (Harvard Apparatus Co., Inc., Millis, Mass.) for $55 \mathrm{~min}$ after an initial priming dose of $125 \mathrm{mg} / \mathrm{kg}$. During each of the above studies arginine hydrochloride (Cutter Laboratories, Berkeley, Calif.) was infused as a $5 \%$ solution from min 30 through min 55 at a rate of $10 \mathrm{mg} / \mathrm{kg}$ per min.

Determinations. Specimens for determinations of plasma glucose (10), FFA (11), insulin (12), and glucagon levels (13) were obtained at $-30,-10,0,5,10,15,20,30,40$, 50 , and $55 \mathrm{~min}$. Specimens for glucagon and FFA assay were collected in chilled tubes and kept on ice. The tubes for glucagon samples contained $12 \mathrm{mg}$ EDTA and $0.5 \mathrm{M}$ benzamidine (14) (Aldrich Chemical Co., Inc., Milwaukee, Wis.) in volumes of $0.7 \mathrm{ml}$. Plasma was centrifuged at $4^{\circ} \mathrm{C}$ and subsequently transferred to storage at $-20^{\circ} \mathrm{C}$ until time of assay not more than 4 wk later. Glucagon was measured in triplicate by immunoassay (13) using the specific Unger antiserum $30 \mathrm{~K}$ (purchased from the Diabetes Research Fund, University of Texas Southwestern Medical School at Dallas, Dallas, Texas). For glucagon values between 100 and $200 \mathrm{pg} / \mathrm{ml}$ the intraassay coefficient of variation is $9 \%$ and the interassay coefficient is $14 \%$. Neither nicotinic acid nor heparin was found to interfere with the glucagon immunoassay.

Statistic analysis. Data were analyzed for statistical significance by using a two-tailed paired Student's $t$ test.

\section{RESULTS}

Effect of acute elevation of plasma FFA on plasma glucose, insulin, and glucagon levels (Fig. 1). Heparin administration resulted in an acute elevation of plasma FFA from a mean ( \pm SE) control value of $0.489 \pm$ $0.036 \mathrm{mM}$ to $0.712 \pm 0.055 \mathrm{mM}(P<0.003)$. Plasma glucagon declined rapidly from a mean ( $\pm \mathrm{SE}$ ) control value of $122 \pm 15 \mathrm{pg} / \mathrm{ml}$ to $67 \pm 13 \mathrm{pg} / \mathrm{ml}(P<0.001)$ by $5 \mathrm{~min}$. At this time plasma FFA had risen only 0.081 $\mathrm{mM}$. The maximum decrease in plasma glucagon to $58 \pm 14 \mathrm{pg} / \mathrm{ml}$ occurred at $20 \mathrm{~min}$. Plasma glucose levels did not change during the initial $10 \mathrm{~min}$ but rose slightly thereafter from a mean $( \pm S E)$ control value of $84 \pm 1.7$ $\mathrm{mg} / 100 \mathrm{ml}$ to $88 \pm 2 \mathrm{mg} / 100 \mathrm{ml}(P<0.002)$ by $30 \mathrm{~min}$.
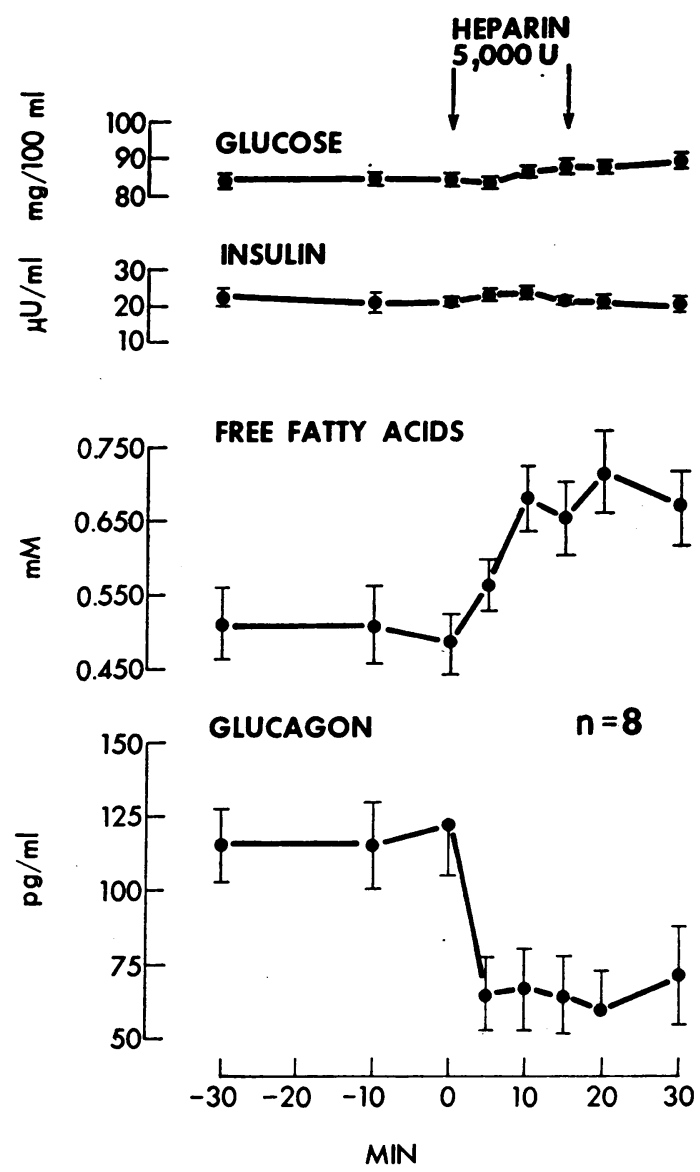

Figure 1 Effects of heparin administration on plasma glucose, insulin, FFA, and glucagon levels, mean $\pm \mathrm{SE}$.

There was no significant change in plasma insulin levels during the entire 30 -min period.

Effect of acute lowering of plasma FFA on plasma glucose, insulin, and glucagon levels (Fig. 2). Nicotinic acid administration resulted in an acute lowering of plasma FFA from a mean ( $\pm \mathrm{SE}$ ) control value of $0.520 \pm 0.046 \mathrm{mM}$ to $0.252 \pm 0.041 \mathrm{mM}(P<0.0001)$. This was accompanied by a rise in plasma glucagon from a mean ( $\pm \mathrm{SE}$ ) control value of $113 \pm 18 \mathrm{pg} / \mathrm{ml}$ to a maximum of $168 \pm 12 \mathrm{pg} / \mathrm{ml}(P<0.004)$ at $20 \mathrm{~min}$. Plasma glucagon rose within $10 \mathrm{~min}$ and remained elevated above control levels for the remainder of the 30 min period. No change in either plasma glucose or plasma insulin levels occurred.

Effects of glucose infusion on plasma glucose, $F F A$, insulin, and glucagon levels (Fig. 3). Since hyperglycemia is known to lower plasma glucagon levels, glucose infusions $(350 \mathrm{mg} / \mathrm{min}$ ) were performed in order to compare the relative ability of glucose and FFA to suppress glucagon secretion. Hyperglycemia averaging 149-161 mg/100 ml was maintained for $30 \mathrm{~min}$. Plasma 

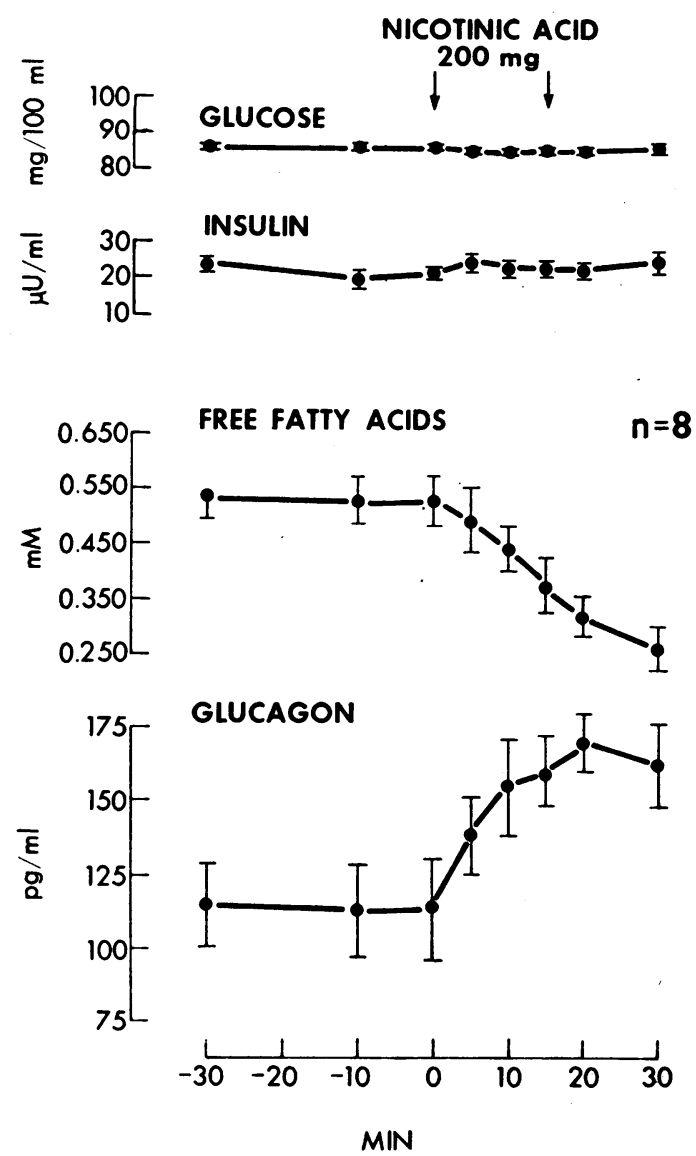

FIGURE 2 Effects of nicotinic acid administration on plasma glucose, insulin, FFA, and glucagon levels, mean \pm SE.

glucagon levels declined gradually from a mean ( $\pm S E$ ) control level of $101 \pm 16 \mathrm{pg} / \mathrm{ml}$ to a nadir at $30 \mathrm{~min}$. of $57 \pm 16 \mathrm{pg} / \mathrm{ml}(P<0.005)$. Plasma FFA levels declined progressively from a mean ( $\pm \mathrm{SE}$ ) control level of $0.413 \pm 0.031 \mathrm{mM}$ to $0.248 \pm 0.017 \mathrm{mM}$ at $30 \mathrm{~min}$. Plasma insulin rose abruptly from a mean ( $\pm \mathrm{SE}$ ) control of $19 \pm 2 \mu \mathrm{U} / \mathrm{ml}$ to $47 \pm 7.5 \mu \mathrm{U} / \mathrm{ml}$ at $10 \mathrm{~min}$ and subsequently averaged between $30-33 \mu \mathrm{U} / \mathrm{ml}$ for the remaining $20 \mathrm{~min}$.

Effects of alterations in plasma FFA and hyperglycemia on glucose, insulin, and glucagon responses to arginine infusion (Table $I$ ). In order to further assess the effect of alterations in plasma FFA levels on pancreatic alpha cell function, infusions of arginine (10 $\mathrm{mg} / \mathrm{kg}$ per $\mathrm{min}$ ) were begun $30 \mathrm{~min}$ after the administration of heparin, nicotinic acid, or glucose, and were continued for $25 \mathrm{~min}$. In control studies arginine was infused over $25 \mathrm{~min}$ after a 30 -min equilibration period. Total glucagon, insulin, and glucose responses were calculated from areas under the curve during administration of arginine. After heparin-induced elevation of plasma FFA, glucagon and glucose responses to arginine were diminished while insulin responses were unaltered. After nicotinic acid-induced lowering of plasma FFA, glucagon responses to arginine were not significantly different from control arginine studies. However, glucose and insulin responses to arginine were diminished significantly. Infusion of glucose resulted in marked augmentation of insulin responses to arginine and diminution of glucagon responses. Plasma glucose levels declined during the arginine infusions despite continued infusion of glucose. Thus a significant

TABLE I

Effect of Heparin, Nicotinic Acid, and Glucose Administration on Plasma Glucose, Insulin, and Glucagon Responses to Arginine Infusion (Areas under the Curve)

\begin{tabular}{|c|c|c|c|c|}
\hline Subject & Control & Heparin & Nicotinic acid & Glucose \\
\hline \multicolumn{5}{|c|}{ Glucose $(\mathrm{mg} / 100 \mathrm{ml} \cdot \mathrm{min})$} \\
\hline C. $\mathrm{O}$. & 432 & 275 & 275 & 330 \\
\hline H. E. & 550 & 60 & 73 & -198 \\
\hline A. L. & 255 & 165 & 130 & -322 \\
\hline L. E. & 327 & 115 & 175 & -270 \\
\hline P. L. & 398 & 210 & 352 & -77 \\
\hline N. $O$. & 63 & 247 & 317 & 185 \\
\hline H. E. & 378 & 180 & 98 & -257 \\
\hline T. Y. & 338 & 165 & 207 & -213 \\
\hline Mean & 342.6 & 177.1 & 203.2 & -102.8 \\
\hline$\pm \mathrm{SE}$ & 50.3 & 24.4 & 36.1 & 82.9 \\
\hline$P<$ & & 0.01 & 0.02 & 0.001 \\
\hline \multicolumn{5}{|c|}{ Insulin $(\mu U / m l \cdot \min )$} \\
\hline C. 0 . & 655 & 588 & 388 & 2,343 \\
\hline H. E. & 443 & 235 & 315 & 3,560 \\
\hline A. L. & 598 & 450 & 183 & 2,655 \\
\hline L. E. & 635 & 530 & 73 & 1,442 \\
\hline P.L. & 1,185 & 1,260 & 687 & 3,575 \\
\hline N. O. & 183 & 345 & 150 & 3,600 \\
\hline H. E. & 170 & 98 & 130 & 1,010 \\
\hline T. Y. & 205 & 302 & 217 & 1,215 \\
\hline Mean & 509.3 & 476.6 & 267.8 & $2,487.5$ \\
\hline$\pm \mathrm{SE}$ & 121.0 & 125.1 & 69.8 & 392.3 \\
\hline $\bar{P}<$ & & NS & 0.02 & 0.0001 \\
\hline \multicolumn{5}{|c|}{ Glucagon $(p g / m l \cdot m i n)$} \\
\hline C. $\mathrm{O}$. & 4,300 & 1,075 & 1,412 & 3,325 \\
\hline H. E. & 4,770 & 5,737 & 4,607 & 3,550 \\
\hline A. L. & 3,950 & 4,466 & 3,385 & 2,210 \\
\hline L. E. & 5,912 & 2,300 & 8,150 & 6,470 \\
\hline P. L. & 7,450 & 4,162 & 8,537 & 5,000 \\
\hline N. O. & 5,350 & 1,525 & 3,137 & 900 \\
\hline H. E. & 4,455 & 4,412 & 4,922 & 4,395 \\
\hline T. Y. & 3,218 & 1,095 & 2,575 & 1,808 \\
\hline Mean & $4,925.9$ & $3,095.7$ & 4,590 & $3,457.2$ \\
\hline$\pm \mathrm{SE}$ & 463.5 & 639.3 & 907 & 643.3 \\
\hline$P<$ & & 0.01 & NS & 0.02 \\
\hline
\end{tabular}


negative glucose response was observed. In all procedures, including control studies, plasma FFA declined during infusion of arginine.

\section{DISCUSSION}

The present investigation was undertaken to determine whether alterations in plasma FFA levels affect glucagon secretion in man. Elevation of plasma FFA from 0.478 $\mathrm{mM}$ to $0.712 \mathrm{mM}$ after heparin administration suppressed plasma glucagon levels approximately $50 \%$ in the eight normal subjects studied. Conversely, depression of plasma FFA from $0.520 \mathrm{mM}$ to $0.250 \mathrm{mM}$ after nicotinic acid administration raised plasma glucagon levels approximately $50 \%$. These results thus indicate that rather small alterations of plasma FFA within the physiologic range have a significant effect on glucagon secretion in man.

Similar in vivo effects of plasma FFA on glucagon secretion have been previously reported in dogs (5-7). Seyffert and Madison (5) found that elevation of plasma FFA from $0.392 \mathrm{mM}$ to $0.800 \mathrm{mM}$ after heparin and Lipomul (The Upjohn Company, Kalamazoo, Mich.) administration resulted in a $30 \%$ fall in plasma glucagon levels below baseline. In instances when heparin and Lipomul administration failed to raise plasma FFA (6), there was no change in plasma glucagon levels, thus indicating that the results were unlikely to be due to the administration of heparin per se distinct from its ability to raise plasma FFA levels. Luyckx and Lefebvre (7) found that depression of plasma FFA from $0.614 \mathrm{mM}$ to $0.374 \mathrm{mM}$ after nicotinic acid administration to dogs resulted in a rise of plasma glucagon levels $60 \%$ above base line in specimens obtained directly from the pancreatico-duodenal vein. A similar elevation of plasma glucagon levels has been reported by Andrews and Blackard in man during infusion of nicotinic acid (9). In all these studies, changes in plasma glucagon levels either preceded or were unaccompanied by significant alteration in plasma glucose, amino nitrogen, insulin, and ketone body levels. Furthermore, preliminary experiments in our laboratory demonstrate that nicotinic acid itself has no effect on glucagon release from the isolated perfused rat pancreas. These observations thus suggest that plasma FFA had directly affected glucagon secretion.

Further evidence for this conclusion is provided by the in vitro studies of Edwards, Howell, and Taylor $(3,4)$ demonstrating that $5 \mathrm{mM}$ octanoate diminishes glucagon release from guinea pig islets by approximately $50 \%$. Inhibition of octanoate oxidation reversed this suppression and resulted in augmented glucagon release (3). It is of interest that under these in vitro conditions $16.7 \mathrm{mM}$ glucose was required to diminish glucagon secretion. $5.5 \mathrm{mM}$ glucose, a concentration

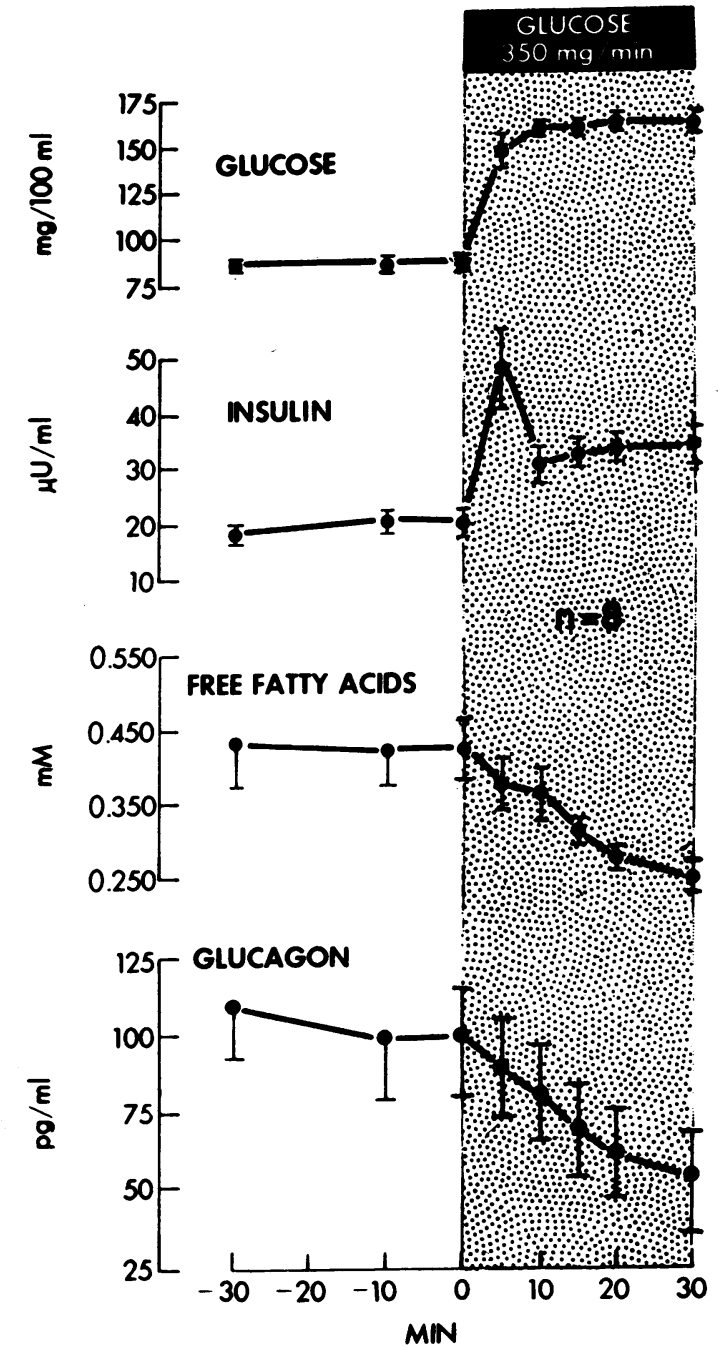

Figure 3 Plasma glucose, insulin, FFA, and glucagon levels during infusion of glucose, mean $\pm \mathrm{SE}$.

similar to that at which octanoate suppressed glucagon release, had no effect, Luyckx, Massi-Benedetti, and Lefebvre have reported that high levels of FFA inhibit the glucagon response to lack of glucose in the isolated perfused rat pancreas (8). These results suggest that pancreatic alpha cell function might be more sensitive to changes in FFA than to glucose.

This point was examined in the present study by comparing the suppression of plasma glucagon levels after elevation of FFA to the suppression following hyperglycemia. With infusion of glucose, plasma glucose levels rose from $4.8 \mathrm{mM}$ to approximately $8.8 \mathrm{mM}$. In response, plasma glucagon levels declined gradually over $30 \mathrm{~min}$ to $58 \%$ of the base-line value. With an elevation of plasma FFA from 0.478 to only $0.559 \mathrm{mM}$, plasma glucagon levels fell to $56 \%$ of base line within $5 \mathrm{~min}$. Thus, although both glucose and FFA suppressed plasma glu-

Effect of FFA on Glucagon Secretion 
cagon levels to a similar nadir of $58 \mathrm{pg} / \mathrm{ml}$, the gradual diminution of plasma glucagon during hyperglycemia was in contrast to much more rapid fall accompanying a rise in plasma FFA. A possible explanation for the apparent greater sensitivity of the pancreatic alpha cell to FFA might be that the observed glucagon responses to glucose in vivo represent the net effect of two different processes-stimulation from a fall in plasma FFA and suppression by hyperglycemia. Moreover since no rise in plasma glucagon occurred during infusion of glucose despite a fall in plasma FFA levels, it is apparent that the influence of glucose on pancreatic alpha cell function predominates over that of FFA.

Both glucagon and glucose responses to arginine were diminished after heparin-induced elevation of plasma FFA while no change occurred in plasma insulin responses. Since Seyffert and Madison (5) have shown in the dog that elevation of plasma FFA diminishes plasma glucagon levels and hepatic glucose output, it is thus possible that the lower plasma glucose responses during infusion of arginine with heparin pretreatment were the result of less glucagon-induced glycogenolysis. After diminution of plasma FFA by administration of nicotinic acid, glucagon responses to arginine were similar to those of control studies. This lack of augmentation of glucagon responses during arginine infusion may have occurred in part because of the elevation of basal plasma glucagon levels caused by prior diminution of plasma FFA and also because diminution of plasma FFA normally occurs during infusion of arginine. In a recent abstract (9), Andrews and Blackard reported lack of suppression of glucagon responses to arginine after elevation of plasma FFA by i.v. infusion of a soybean emulsion plus heparin or by oral administration of a corn emulsion plus heparin. Except for differences in experimental design, reasons for this discrepancy are not apparent.

Infusion of glucose diminished glucagon responses to arginine, and insulin responses were markedly augmented. Synergism of glucose and arginine in stimulating insulin secretion has previously been noted in man (15). It is pertinent that the glucagon responses were diminished despite lowering of plasma FFA. These results again suggest the supremacy of glucose in modulating pancreatic alpha function. Glucose responses to arginine were also diminished. In fact despite constant glucose infusion, plasma glucose levels declined during arginine. Similar observations have been reported in the dog (16), and probably occur because enhanced insulin responses stimulate peripheral glucose uptake and exert effects on the liver which predominate over those of glucagon.

The physiologic significance of these findings is unclear. However FFA, the predominant fuel in man, have been shown in the present study to influence human glucagon secretion in a manner consistent with the prevailing concept that the pancreatic alpha cell plays an important role in nutrient homeostasis. Previously it has been shown in the dog that an increase in plasma FFA stimulates insulin release $(5,17)$ while in man a diminution in FFA lowers plasma insulin levels (18). Thus FFA, like glucose, may cause reciprocal changes in human glucagon and insulin secretion. Since these hormones have antagonistic effects on glucose metabolism this may represent another mechanism by which FFA influence glucose homeostasis (19). The effects of FFA on glucagon secretion may also affect adipose tissue function since glucagon is lipolytic (20). Indeed, it has been suggested that plasma FFA may participate in a feedback regulation of lipolysis during starvation by permitting insulin secretion to occur despite a falling plasma glucose level (5). Part of such a proposed feedback system might also involve limitation of glucagon secretion by rising plasma FFA levels. This is in accord with observations that during the initial $72 \mathrm{~h}$ of fasting both plasma glucagon and FFA levels rise but subsequently plasma FFA remain stable while plasma glucagon declines to levels slightly above prefast values (21). A different situation may prevail during ketoacidosis when plasma glucagon levels may be elevated (22) despite concomitant elevation of plasma FFA and glucose. The suppressive effect of FFA on glucagon secretion may be an insulin-dependent process similar to that of glucose. Moreover, disruption of normal glucose metabolism and enhanced catecholamine release (23) may supercede the effects of FFA on the pancreatic alpha cell.

\section{ACKNOWLEDGMENTS}

The authors thank Ms. Gail Gustafson, Ann Aldridge, and Mr. Shiro Horita, for excellent technical help, and Mrs. Dorothea Faber for editorial assistance.

This work was supported in part by grants from The Levi J. and Mary C. Skaggs, Foundation, Oakland, Calif. and The Susan Greenwall Foundation, Inc., New York.

\section{REFERENCES}

1. Unger, R. H. 1971. Glucagon physiology and pathophysiology. N. Engl. J. Med. 285 : 443.

2. Edwards, J., C. Hellerstrom, B. Petersson, and K. W. Taylor. 1972. Oxidation of glucose and fatty acids in normal and in $\mathrm{A}_{\mathbf{2}}$-cell rich pancreatic islets isolated from guinea pigs. Diabetologia. 8: 93.

3. Edwards, J. C., and K. W. Taylor. 1970. Fatty acids and the release of glucagon from isolated guinea-pig islets of langerhans incubated in vitro. Biochim. Biophys. Acta. 215: 310.

4. Edwards, J. C., S. L. Howell, and K. W. Taylor. 1969. Fatty acids as regulators of glucagon secretion. Nature (Lond.). 224: 808.

5. Seyffert, W., and L. L. Madison. 1967. Physiologic 
effects of metabolic fuels on carbohydrate metabolism. I. Acute effect of elevation of plasma free fatty acids on hepatic glucose output, peripheral glucose utilization, serum insulin and plasma glucagon levels. Diabetes. 16: 765.

6. Madison, L. L., W. A. Seyffert, R. H. Unger, and B. Barker. 1968. Effect of plasma free fatty acids on plasma glucagon and insulin levels. Metab. (Clin. Exp.). $17: 301$.

7. Luyckx, A., and P. J. Lefebvre. 1970. Arguments for 2 regulation of pancreatic glucagon secretion by circulating plasma free fatty acids. Proc. Soc. Expl. Biol. Med. 133 : 524.

8. Luyckx, A., F. Massi-Benedetti, and P. Lefebvre. 1972. Glucagon response to hypoglycemia in isolated perfused rat pancreas and its modifications by circulating levels of free fatty acids. Diabetologia. 8: 56. (Abstr.).

9. Andrews, S. S., and W. W. Blackard. 1973. Effect of free fatty acids on glucagon secretion in man. $E x$ cerpta Med. Int. Congr. Ser. 280: 41. (Abstr.).

10. ERA. 2001 Glucose Analyzer Beckman Instructions 83557-A, Beckman Instruments Inc., Fullerton, Calif.

11. Laurell, S., and G. Tibbling. 1967. Colorimetric microdetermination of free fatty acids in plasma. Clin. Chim. Acta. $16: 57$.

12. Grodsky, G. M., and P. H. Forsham. 1960. An immunochemical assay of total extractable insulin in man. J. Clin. Invest. 39: 1070.

13. Unger, R., and A. Eisentraut. 1968. Glucagon. In Hormones in Blood. C. Grey, editor. Academic Press, Inc., New York. 2nd edition, Vol. 1. 83-128.

14. Ensinck, J. W., C. Shepard, R. J. Dudl, and R. H.
Williams. 1972. Use of benzamidine as a proteolytic inhibitor in the radioimmunoassay of glucagon in plasma. J. Clin. Endocrinol. Metab. 35: 463.

15. Levin, S. R., J. H. Karam, S. Hane, G. M. Grodsky, and P. H. Forsham. 1971. Enhancement of arginineinduced insulin secretion in man by prior administration of glucose. Diabetes. 20: 171.

16. Unger, R. H., A. Ohneda, E. Aguilar-Parada, and A. M. Eisentraut. 1969. The role of aminogenic glucagon secretion in blood glucose homeostasis. J. Clin. Invest. $48: 810$.

17. Crespin, S. R., W. B. Greenough, III, and D. Steinberg. 1973. Stimulation of insulin secretion by longchain free fatty acids, a direct pancreatic effect. $J$. Clin. Invest. 52: 1973.

18. Balasse, E. O., and H. A. Ooms. 1973. Role of plasma free fatty acids in the control of insulin secretion in man. Diabetologia. 9 : 145.

19. Ruderman, N. B., C. Toews, and E. Shafir. 1969. Role of free fatty acids in glucose homeostasis. Arch. Int. Med. 123 : 299.

20. Lefebvre, P. 1966. The physiologic effect of glucagon on fat-mobilization. Diabetologia. 2: 130.

21. Aguilar-Parada, E., A. Eisentraut, and R. H. Unger. 1969. Effect of starvation on plasma pancreatic glucagon in normal man. Diabetes. 18: 717.

22. Müller, W. A., G. R. Faloona, and R. H. Unger. 1973. Hyperglucagonemia in ketoacidosis: its prevalence and significance. Am. J. Med. $54: 52$.

23. Gerich, J. E., J. H. Karam, and P. H. Forsham. 1973. Stimulation of glucagon secretion by epinephrine in man. J. Clin. Endocrinol. Metab. $37: 479$. 